\title{
ANALYSIS OF A BRAZILIAN THERMAL PLANT OPERATION APPLYING ENERGETIC AND EXERGETIC BALANCES
}

\author{
M. M. C. Fraga ${ }^{1}$, B. L. de O. Campos ${ }^{1 *}$, M. S. Lisboa ${ }^{2}$, \\ T. B. de Almeida ${ }^{2}$, A. O. S. da Costa ${ }^{1}$ and V. de F. C. Lins ${ }^{1}$ \\ ${ }^{1}$ Universidade Federal de Minas Gerais - Chemical Engineering, Av. Pres. Antônio Carlos 6627, Pampulha, \\ Belo Horizonte, MG, 31270-901, Brazil. \\ ${ }^{2}$ CEMIG Geração e Transmissão S.A., Juatuba, MG, Brazil.
}

(Submitted: August 9, 2017 ; Revised: December 9, 2017 ; Accepted: January 3, 2018)

\begin{abstract}
When the level of water reservoirs from Brazilian hydroelectric stations is low, additional thermal plants are turned on to complement the power of the national electric system. The fuels used in these plants are generally natural gas, fuel oil and coal. The objective of this work is to analyze energetically and exergetically a fuel oil thermal plant in operation in Brazil. Real industrial data were used in this analysis. The calculated total work of the turbine is $120.73 \mathrm{MW}$, which is close to the real value of $120 \mathrm{MW}$. The cycle energetic efficiency is $36.8 \%$ and the exergetic efficiency is $34.4 \%$. The highest exergy destruction was found to be in the boiler $(177.11$ MW), followed by the high pressure turbine (13.37 MW), due to larger irreversibilities in the processes of these equipment. The exergetic analysis functioned as a complement to the energetic analysis, pointing out where the greatest irreversibilities and improvement potential are: in the boiler.

Keywords: Electrical power generation; Efficiency; Exergy destruction.
\end{abstract}

\section{INTRODUCTION}

In Brazil, there is an interconnected system of electrical energy generation and distribution, which has a continental dimension and an installed capacity of 151.89 GW (MME, 2017). This system, called "Sistema Interligado Nacional" (SIN), is responsible for about $98 \%$ of national electrical energy consumption. The basis of the Brazilian energetic matrix is hydroelectric energy, which generates about $64.6 \%$ of the electrical energy of the country (MME, 2017). The other main sources of electrical energy are: thermal energy $(28.5 \%)$, wind $(6.9 \%)$ and solar energy (less than $0.1 \%$ ). Because of economic reasons, Brazilian nuclear power plants operate uninterruptedly, as well as some of the other thermal power plants. On the other hand, some thermal plants are turned on to complement the power of the system when the level of water reservoirs from hydroelectric stations is low, as a consequence of the seasonal rainfall regime (Borba et al., 2012). The "Operador Nacional do Sistema Elétrico" (ONS) is a private non-profit Brazilian entity that is responsible for coordinating and controlling the operation of the SIN electricity generation and transmission facilities under supervision and regulation of the National Electric Energy Agency (ANEEL) of Brazil. The ONS has the responsibility to dispatch regional thermal plant units. The dispatch of thermal power plants is determined by operational costs and according to the system demands (Rego, 2013). The main fuel of Brazilian thermal plants is biomass $(9.4 \%$ of the whole installed capacity), followed by natural gas ( $8.5 \%)$, oil (6.8\%) and coal (2.4\%) (MME, 2017).

Many studies included energetic and exergetic analyses of systems (Araújo et al., 2007; Pambudi et al., 2014; Rego, 2013; Sordi et al., 2009; Utlu et al., 2006).

\footnotetext{
*Corresponding author: brunolacerdaoc@gmail.com
} 
In some cases, it is specifically applied to thermal power plants (Adibhatla and Kaushik, 2014; Aminov et al., 2013; Aljundi, 2009; Kamate and Gangavati, 2009; Kaushik et al, 2015; Regulagadda et al., 2010; Rosen and Dincer, 2003). Regulagadda et al. (2010) emphasize the limitations of an energetic analysis of the thermodynamic cycle, since it does not consider system irreversibilities, environmental conditions and the degradation of energy quality. Therefore, an exergetic analysis may be applied to minimize the limitations of the energy balance (Regulagadda et al., 2010).

The objective of this work is to analyze energetically and exergetically a fuel oil thermal power plant in operation, which is located in the state of Minas Gerais, Brazil. Real industrial data are used in this analysis. The operating conditions used in this work were reported directly from plant operators and represent actual adopted values in daily operations.

\section{SYSTEM DESCRIPTION}

The Igarapé Thermal Power Plant was built in 1978 and its operation started with an installed capacity of
125 MW. In 1999, after some modifications, its capacity was increased to $131 \mathrm{MW}$. The energy source of the plant is fuel oil 1A. The power delivered from the plant to the electrical system varies according to the demand of ONS. In this work, operational conditions that result in a gross power output of $120 \mathrm{MW}$ are considered.

The process of electrical energy generation in this plant consists of a Rankine cycle, and a simplified flow diagram of the plant is shown in Fig. 1. The water stream extracted from the condenser (1) enters the condensate extraction pump (CEP) to be pressurized. It then passes through low pressure heaters (LPH1 and LPH2), where it receives heat from the vapor extractions (I) and (II), which come from the low pressure turbine (LPT). The partially heated water stream (4) enters the deaerator (DE), which operates counter currently to remove dissolved oxygen. In this equipment, there is also addition of the vapor extraction (III), which comes from the medium pressure turbine (MPT), and addition of the liquid extraction (B), which comes from the high pressure heater (HPH1). Water stream (5) moves to the boiler feed pump (BFP), where it is once again pressurized, and passes through the high pressure heaters (HPH1 and HPH 2).

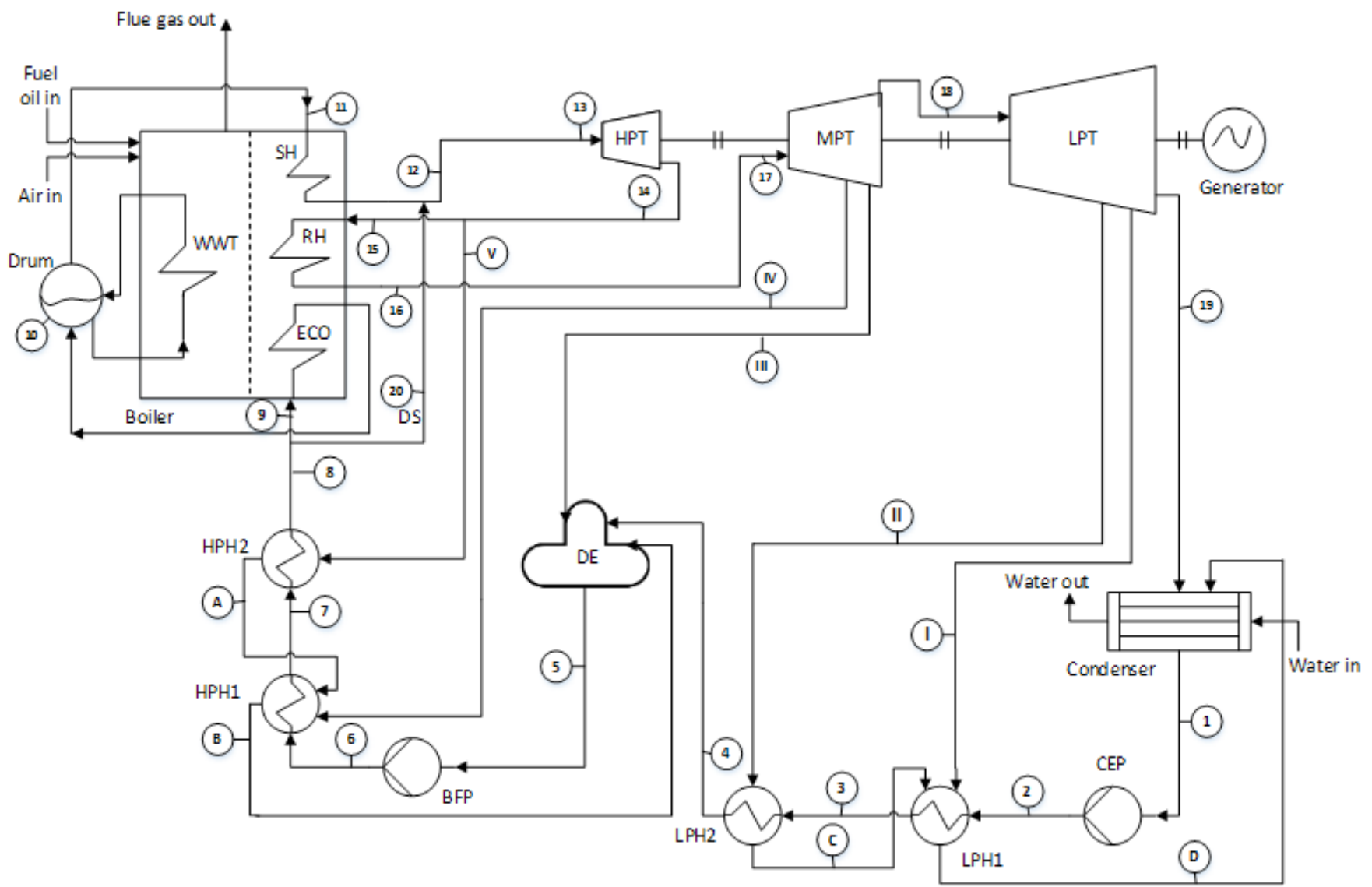

Figure 1. Process flow diagram: BFP - Boiler Feed Pump; CEP - Condensate Extraction Pump; DE - Deaerator; DS - Desuperheater; ECO - Economizer; HPH - High Pressure Heater; HPT - High Pressure Turbine; LPH - Low Pressure Heater; LPT - Low Pressure Turbine; MPT - Medium Pressure Turbine; RH - Reheater; SH - Superheater; WWT - Water Wall Tubes. 
Heat received in these equipments is from extractions (IV) and (V), which come from the medium pressure (MPT) and high pressure turbines (HPT) respectively. The following stream (8) is split into stream (9) and the desuperheater (DS) stream (20). The latter bypasses the boiler to control its output temperature. Stream (9) enters the boiler and is heated in various sections. After passing through the economizer (ECO), the water stream enters the drum. It recirculates through the water wall tubes (WWT), and saturated vapor leaves the drum. Vapor stream (11) enters the superheater (SH) and is then mixed with stream (20). Stream (13) enters the HPT and does work. The output vapor stream (14) is split into stream (15) and into extraction (V). Stream (15) returns to the boiler and passes through the reheater (RH). Stream (17) enters the MPT and does work. Three streams leave the MPT: extraction (IV), extraction (III), and stream (18); the latter enters the LPT and does work. The LPT has three output streams: extraction (II), extraction (I), and stream (19). The latter flows into the condenser, where it is cooled at low pressure, closing the water cycle.

\section{CALCULATION METHODOLOGY}

Table 1 shows real data of the streams 1 to 19 provided by plant operators. Enthalpy and entropy from each stream were obtained using public software from Zittau/Goerlitz University (Zittau's Fluid Property Calculator, 2017).

Some considerations were made for the calculations:

The process is in the steady-state;

Kinetic and potential energy variations are neglected;

The auxiliary vapor system used to heat the fuel oil tubes and the vacuum system ejectors are neglected;

Table 1. Real data from plant operation.

\begin{tabular}{cccc}
\hline $\mathbf{i}$ & $\begin{array}{c}\mathbf{T} \\
(\mathbf{K})\end{array}$ & $\begin{array}{c}\mathbf{P} \\
(\mathbf{M P a})\end{array}$ & $\begin{array}{c}\dot{\boldsymbol{m}} \\
\left(\mathbf{k g} \cdot \mathbf{s}^{-\mathbf{1}} \mathbf{)}\right.\end{array}$ \\
\hline 1 & 319.15 & 0.0474 & - \\
2 & - & 1.965 & - \\
3 & 343.15 & - & - \\
4 & 378.15 & - & - \\
5 & 424.15 & 0.494 & 114.72 \\
6 & 428.15 & 15.988 & - \\
7 & 463.15 & - & - \\
8 & 508.15 & - & - \\
9 & - & 15.302 & - \\
10 & 526.65 & - & - \\
11 & - & 14.909 & - \\
12 & 804.15 & 13.635 & - \\
13 & 802.65 & 12.948 & - \\
14 & 688.65 & 3.329 & - \\
16 & 810.65 & - & - \\
19 & - & 0.0114 & 2.78 \\
20 & - & - &
\end{tabular}

Heat loss in the heaters is neglected;

The operation in $\mathrm{SH}, \mathrm{RH}, \mathrm{HPH} 1, \mathrm{HPH} 2$, LPH1, and LPH2 is isobaric;

The turbines and the pumps operate adiabatically;

The temperature of stream (2) was estimated at $320.15 \mathrm{~K}$;

Extraction (I) is saturated vapor;

The streams leaving the heater (A-D) and leaving the deaerator (stream 5) are saturated liquids;

The fuel oil is an incompressible fluid and has a constant heat capacity;

The reference temperature is $298.15 \mathrm{~K}$;

Table 2 presents real pressure data of the extractions (I-V).

The temperatures of the extractions (II), (III), (IV), and stream (19) were calculated with interpolations. Temperature, pressure, and entropy data from the vapor table were used, as well as thermodynamic properties of extraction (I) and stream (17). The mass flow rates of streams $(1-4 ; 6-19)$ were calculated in mass balances. The mass flow rates of extractions (I$\mathrm{V})$ were calculated in energy balances and are shown in Equations (1a-1e).

$$
\begin{aligned}
& \dot{m}_{V}=\frac{\dot{m}_{7} \cdot\left(h_{8}-h_{7}\right)}{\left(h_{V}-h_{A}\right)} \\
& \dot{m}_{I V}=\frac{\left[\dot{m}_{6} \cdot\left(h_{7}-h_{6}\right)-\dot{m}_{V} \cdot\left(h_{A}-h_{B}\right)\right]}{\left(h_{I V}-h_{B}\right)} \\
& \dot{m}_{I I I}=\frac{\left[\dot{m}_{5} \cdot\left(h_{5}-h_{4}\right)-\left(\dot{m}_{V}+\dot{m}_{I V}\right) \cdot\left(h_{B}-h_{4}\right)\right]}{\left(h_{I I I}-h_{4}\right)}
\end{aligned}
$$

$\dot{m}_{I I}=\frac{\dot{m}_{3} \cdot\left(h_{4}-h_{3}\right)}{\left(h_{I I}-h_{C}\right)}$

$\dot{m}_{I}=\frac{\left[\dot{m}_{2} \cdot\left(h_{3}-h_{2}\right)-\dot{m}_{I I} \cdot\left(h_{C}-h_{D}\right)\right]}{\left(h_{I}-h_{D}\right)}$

Work rate $(\dot{W})$ and specific work (w) of turbines and pumps are calculated from the energy balance, as shown in Equations (2) and (3), respectively, where n is the number of output streams. As there are no data

Table 2. Real pressure data from turbine extractions.

\begin{tabular}{cc}
\hline Extraction & P (MPa) \\
\hline I & 0.0474 \\
II & 0.131 \\
III & 0.592 \\
IV & 1.376 \\
V & 3.239 \\
\hline
\end{tabular}


from stream (18), the work of the MPT and LPT are calculated together.

$\dot{W}=\sum_{i=1}^{n}\left[\dot{m}_{\text {out }, i} \cdot\left(h_{\text {in }}-h_{\text {out }, i}\right)\right]-\left|\dot{Q}_{L}\right|$

$w=\frac{\dot{W}}{\dot{m}_{i n}}$

The total work rate of the turbines $\left(W_{\mathrm{T}}\right)$ is calculated in Equation (4). The energetic efficiencies of the turbines $\left(\eta_{\mathrm{TEn}}\right)$ and the pumps $\left(\eta_{\mathrm{B}, \mathrm{En}}\right)$ are obtained from Equations (5) and (6) respectively.

$\dot{W}_{T}=\dot{W}_{M P T / L P T}+\dot{W}_{H P T}$

$\eta_{T, E n}=\frac{\dot{W}}{\left(\dot{W}+\left|\dot{Q}_{L}\right|\right)}$

$\eta_{P, E n}=\frac{\left(\dot{W}-\left|\dot{Q}_{L}\right|\right)}{\dot{W}}$

The heat rate output in the condenser $\left(\dot{Q}_{C}\right)$ and the specific heat output in the condenser $\left(\mathrm{q}_{\mathrm{c}}\right)$ are calculated in Equations (7) and (8) respectively.

$\dot{Q}_{C}=\dot{m}_{19} \cdot\left(h_{19}-h_{1}\right)+\left(\dot{m}_{I}+\dot{m}_{I I}\right) \cdot\left(h_{D}-h_{1}\right)$

$q_{C}=\frac{\dot{Q}_{C}}{\dot{m}_{1}}$

The heat rate input in the boiler $\left(\dot{Q}_{B}\right)$ and the specific heat input in the boiler $\left(q_{B}\right)$ are shown in Equations (9) and (10) respectively.

$\dot{Q}_{B}=\dot{m}_{8} \cdot\left(h_{12}-h_{8}\right)+\dot{m}_{15} \cdot\left(h_{16}-h_{15}\right)$

$q_{B}=\frac{\dot{Q}_{B}}{\left(\dot{m}_{12}+\dot{m}_{15}\right)}$

The energetic efficiency of the boiler $\left(\eta_{B E n}\right)$ was calculated based on the lower heating value (LHV) of the fuel, as shown in Equation (11).

$\eta_{B, E n}=\frac{\dot{Q}_{B}}{\left(\dot{m}_{f} \cdot L H V\right)}$

The net power output $(\dot{W})$ and the energetic efficiency of the cycle $\left(\eta_{\mathrm{En}}\right)$ were calculated according to Equations (12) and (13).

$$
\dot{W}_{e}=\dot{W}_{T}-\dot{W}_{B F P}-W_{C E P}
$$

$$
\eta_{E n}=\frac{\dot{W}_{e}}{\left(\dot{m}_{f} \cdot L H V\right)}
$$

The net power output $(\dot{W})$ was also calculated from a global energy balance, which resulted in Equation (14).

$\dot{W}_{e}=\dot{Q}_{B}-\dot{Q}_{C}$

Carnot efficiency $\left(\eta_{\text {Carnot }}\right)$ is calculated in Equation (15), where $\left(W_{\text {rov }}\right)$ is the reversible work rate. The temperature in the boiler $\left(\mathrm{T}_{\mathrm{B}}\right)$ was considered to be $804.15 \mathrm{~K}$, which is the temperature of the stream leaving the superheater (SH) (stream 12). The temperature in the condenser $\left(\mathrm{T}_{\mathrm{C}}\right.$ ) was considered to be $290.15 \mathrm{~K}$, the temperature of water from the river that cools the condenser.

$\eta_{\text {Carnot }}=\frac{\dot{W}_{\text {rev }}}{\dot{Q}_{B}}=\frac{\left(T_{B}-T_{C}\right)}{T_{H}}$

The exergy of the streams, shown in Equation (16), was calculated considering the reference state $\mathrm{T}_{0}=$ $298.15 \mathrm{~K}$ and $\mathrm{P}_{0}=0.101325 \mathrm{MPa}$. Exergy represents the maximum capacity of a stream to do reversible work without heat transfer (Regulagadda et al. 2010).

$e x=h-T_{0} \cdot s-\left(h_{0}-T_{0} \cdot s_{0}\right)$

The exergy balance, shown in Equation (17), associates the variation of exergy $(\mathrm{Ex})$ with heat transfer rate $(\dot{Q})$, work rate $(\dot{W})$, exergy input, exergy output, and exergy destruction rate $\left(I_{d}\right)$. Exergy destruction is associated with generation of irreversibility. Equation (18) shows the calculation of exergy destruction for a steady-state process. Equation (19) shows the calculation for an adiabatic process, as considered in the turbines and pumps.

$$
\begin{aligned}
& \frac{d E x}{d t}=\dot{Q} \cdot\left(\frac{1-T_{0}}{T}\right)-\dot{W}+\sum_{\text {in }}(\dot{m} \cdot e x)-\sum_{\text {out }}(\dot{m} \cdot e x)-\dot{I}_{d} \\
& \dot{I}_{d}=\dot{Q} \cdot\left(\frac{1-T_{0}}{T}\right)-\dot{W}+\sum_{\text {in }}(\dot{m} \cdot e x)-\sum_{\text {out }}(\dot{m} \cdot e x) \\
& \dot{I}_{d}=\sum_{\text {in }}(\dot{m} \cdot e x)-\sum_{\text {out }}(\dot{m} \cdot e x)-\dot{W}
\end{aligned}
$$

The reversible work rate $\left(\dot{W}_{\text {rev }}\right)$, which occurs in the absence of exergy destruction, is calculated in 
Equation (20). Since there are irreversibilities in the process, which lead to exergy destruction, the exergetic efficiencies of the turbines $\left(\eta_{\text {TEx }}\right)$ and the pumps $\left(\eta_{\text {PEx }}\right)$ are calculated in Equations (21) and (22), respectively. The exergy efficiency of the boiler $\left(\eta_{B, E x}\right)$ is defined as the exergy added to the system divided by the exergy of the fuel, as shown in Equation (23).

$\dot{W}_{r e v, \max }=\sum_{\text {in }}(\dot{m} \cdot e x)-\sum_{\text {out }}(\dot{m} \cdot e x)$

$\eta_{T, E x}=\frac{\dot{W}}{\dot{W}_{r e v}}$

$\eta_{P, E x}=\frac{\dot{W}_{r e v}}{\dot{W}}$

$\eta_{B, E x}=\frac{\left[\dot{m}_{8} \cdot\left(e x_{12}-e x_{8}\right)+\left(\dot{m}_{15}\right) \cdot\left(e x_{16}-e x_{15}\right)\right]}{\left(\dot{m}_{f} \cdot e x_{f}\right)}$

The exergy of the fuel $\left(\mathrm{ex}_{\mathrm{f}}\right)$ is the sum of thermomechanical $\left(\mathrm{ex}_{\mathrm{tm}}\right)$ and chemical exergy $\left(\mathrm{ex}_{\mathrm{chem}}\right)$ (Equation 24). The thermo-mechanical exergy $\left(\mathrm{ex}_{\mathrm{tm}}\right)$ is calculated in Equation (25) and the chemical exergy is calculated in Equations (26) and (27), where $z_{i}$ is the mass fraction of the component $i$ in the mixture. Chemical exergy is based on fuel composition and lower heating value (LHV) (Szargut et al., 1988). Tables 3 and 4 present fuel oil, air and flue gas data.

$e x_{f}=e x_{c h e m}+e x_{t m}$

$e x_{t m}=c_{p} \cdot\left(T-T_{0}\right)-T_{0} \cdot c_{p} \cdot \ln \left(\frac{T}{T_{0}}\right)$

$e x_{\text {quim }}=\beta \cdot P C I$

$$
\begin{aligned}
\beta & =1.401+0.1728 \cdot\left(\frac{z_{H}}{z_{C}}\right)+0.0432 \cdot\left(\frac{z_{O}}{z_{C}}\right)+ \\
& +0.2169 \cdot\left(\frac{z_{S}}{z_{C}}\right) \cdot\left(1-2.0628 \cdot \frac{z_{H}}{z_{C}}\right)
\end{aligned}
$$

In order to calculate the exergy destruction in the boiler $\left(\dot{I}_{d, B}\right)$, a control volume in the whole boiler is chosen. For a steady state process $(\mathrm{dEx} / \mathrm{dt}=0)$, no work done $(\dot{W}=0)$, and no heat loss to the environment $(\dot{Q}=0)$, Equation (17) is turned into:

$\dot{I}_{d, B}=\sum_{\text {in }}(\dot{m} \cdot e x)-\sum_{\text {out }}(\dot{m} \cdot e x)$
Table 3. Fuel oil composition.

\begin{tabular}{cc}
\hline Components & Mass fraction \\
\hline Carbon & 0.8493 \\
Hydrogen & 0.1029 \\
Sulfur & 0.0412 \\
Nitrogen & 0.0033 \\
Oxygen & 0.0033 \\
\hline
\end{tabular}

Table 4. Fuel oil, air and flue gas data.

\begin{tabular}{ccc}
\hline Substance & Property & Value \\
\hline Fuel oil & Lower heating value (LHV) & $40166.4 \mathrm{~kJ} \cdot \mathrm{kg}^{-1}$ \\
& Mass flow rate & $7.917 \mathrm{~kg} \cdot \mathrm{s}^{-1}$ \\
& Input temperature & $413.15 \mathrm{~K}$ \\
Air & Heat capacity & $2.303 \mathrm{~kJ} \cdot \mathrm{kg}^{-1} \cdot \mathrm{K}^{-1}$ \\
& Input temperature & $313.15 \mathrm{~K}$ \\
Flue gas & Oxygen excess & $30 \%$ \\
\hline
\end{tabular}

Considering that air is a mixture of nitrogen $\left(\mathrm{N}_{2}\right)$ and oxygen $\left(\mathrm{O}_{2}\right)$, and that the fuel is completely converted into carbon dioxide $\left(\mathrm{CO}_{2}\right)$, water $\left(\mathrm{H}_{2} \mathrm{O}\right)$ and sulfur trioxide $\left(\mathrm{SO}_{3}\right)$ :

$$
\begin{aligned}
\dot{I}_{d, B} & =\dot{m}_{f} \cdot e x_{f}+\dot{m}_{O 2_{2 i}} \cdot e x_{O 2_{2 i}}+\dot{m}_{N 2_{m}} \cdot e x_{N 2_{2 i n}}+ \\
& +\dot{m}_{8} \cdot\left(e x_{8}-e x_{12}\right)+\dot{m}_{15} \cdot\left(e x_{15}-e x_{16}\right)- \\
& -\dot{m}_{C O_{20 u}} \cdot e x_{C O 2_{\text {out }}}-\dot{m}_{H 2 O_{\text {out }}} \cdot e x_{H 22_{\text {out }}}-\dot{m}_{S O 3_{\text {out }}} \cdot e x_{S O 3_{\text {out }}}+ \\
& +\dot{m}_{O 2_{\text {out }}} \cdot e x_{O 2_{\text {out }}}+\dot{m}_{N 2_{\text {out }}} \cdot e x_{N 2_{\text {out }}}
\end{aligned}
$$

The mass flow rate of each air and flue gas component is calculated in a molar balance. The specific heat of each component is a function of temperature, and Equation (30) (Smith et al., 2008) is used to estimate them, where $\mathrm{A}, \mathrm{B}$ and $\mathrm{D}$ are parameters.

$c_{p}(T)=A+B \cdot T+D \cdot T^{-2}$

In order to calculate the exergy of each air and flue gas component, Equation (16) is further developed.

$$
\begin{aligned}
e x= & \int_{T_{o}}^{T} c_{p} d T-T_{0} \cdot \int_{T_{o}}^{T} T^{-1} \cdot c_{p} d T \\
e x & =R \cdot\left\{A \cdot\left[T-T_{0} \cdot\left(1+\ln \left(T / T_{0}\right)\right)\right]+\right. \\
& +\quad B \cdot\left[T^{2} / 2-T \cdot T_{0}+T_{0}^{2} / 2\right]+ \\
& \left.+\quad D \cdot\left[2 \cdot T_{0} / T^{2}-1 / T-1 / T_{0}\right]\right\}
\end{aligned}
$$

The exergetic efficiency of the cycle is the net power output divided by the fuel exergy, as shown in Equation (33).

$n_{E x}=\frac{\dot{W}_{e}}{\left(\dot{m}_{f} \cdot e x_{f}\right)}$ 


\section{RESULTS AND DISCUSSION}

The properties of all streams are organized in Table 5. Fig. 2 shows a diagram of temperature as a function of entropy for all streams. The dotted lines in Fig. 2 emphasize the main cycle and the dashed lines link the vapor extractions to their corresponding condensed streams. Thermodynamic principles of the Rankine cycle may be seen in Fig. 2, like superheating and reheating.

Table 6 shows calculated data of work, efficiency, and exergy destruction of the turbines and the pumps. MPT and LPT showed the best results in both energy and exergy efficiencies. The best results of these turbines in relation to the HPT can be explained by a better ratio of specific volume and blade size of the former, leading to a more adequate residence time and a less irreversible operation.

The irreversibilities in pumps are generally seen in the increase of temperature during compression. Since the temperature of CEP was estimated, it may be the reason why it was less efficient than BFP.

Table 7 shows fuel exergy parameters and Table 8 shows boiler heat input, efficiencies and exergy destruction rate. The energetic efficiency of the boiler was $95.6 \%$, which means that the conversion of chemical energy into internal energy of the steam is considerable. The loss of energy in the boiler is

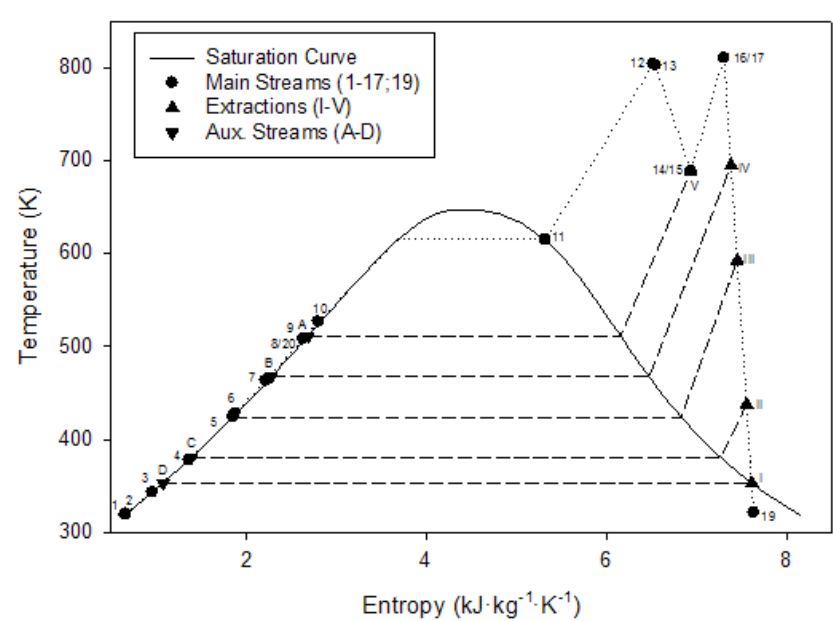

Figure 2. Temperature vs entropy diagram of the Rankine water-steam cycle.

associated with flue gas temperature and heat loss to the environment through equipment walls. The exergy efficiency is $46.9 \%$, which is substantially lower than the energy efficiency. This difference is due to the fact that the exergy efficiency is not only affected by flue gas temperature leaving the boiler and heat loss through equipment walls, but specially by irreversibilities in fuel oil combustion and in heat transfer. The irreversibilities are emphasized in the exergy destruction rate $\left(\dot{I}_{d}\right)$ of the boiler, which was the highest exergy destruction rate in all equipment.

Table 5. Stream properties.

\begin{tabular}{|c|c|c|c|c|c|c|}
\hline i & $\mathbf{T}(\mathrm{K})$ & P(MPa) & $\mathrm{m}\left(\mathrm{kg} \cdot \mathrm{s}^{-1}\right)$ & $\mathrm{s}\left(\mathrm{kJ} \cdot \mathrm{kg}^{-1} \cdot \mathrm{K}^{-1}\right)$ & $\mathrm{h}\left(\mathrm{kJ} \cdot \mathrm{kg}^{-1}\right)$ & ex $\left(k^{\prime} \cdot k^{-1}\right)$ \\
\hline 1 & 319.15 & 0.0474 & 92.20 & 0.652 & 192.65 & 2.90 \\
\hline 2 & 320.15 & 1.965 & 92.20 & 0.664 & 198.50 & 5.10 \\
\hline 3 & 343.15 & 1.965 & 92.20 & 0.954 & 294.60 & 14.77 \\
\hline 4 & 378.15 & 1.965 & 92.20 & 1.362 & 441.58 & 40.16 \\
\hline 5 & 424.15 & 0.489 & 114.72 & 1.852 & 636.57 & 88.93 \\
\hline 6 & 428.15 & 15.988 & 114.72 & 1.875 & 663.31 & 108.76 \\
\hline 7 & 463.15 & 15.988 & 114.72 & 2.215 & 814.59 & 158.79 \\
\hline 8 & 508.15 & 15.988 & 114.72 & 2.630 & 1016.20 & 236.59 \\
\hline 9 & 508.15 & 15.302 & 111.94 & 2.631 & 1016.04 & 236.04 \\
\hline 10 & 526.65 & 14.909 & 111.94 & 2.825 & 1102.65 & 272.47 \\
\hline 11 & 614.81 & 14.909 & 111.94 & 5.317 & 2613.45 & 1032.70 \\
\hline 12 & 804.15 & 13.635 & 114.72 & 6.518 & 3414.30 & 1475.50 \\
\hline 13 & 802.65 & 12.948 & 114.72 & 6.544 & 3417.74 & 1471.10 \\
\hline 14 & 688.65 & 3.239 & 114.72 & 6.935 & 3263.00 & 1199.80 \\
\hline 15 & 688.65 & 3.239 & 104.37 & 6.935 & 3263.00 & 1199.80 \\
\hline 16 & 810.65 & 3.239 & 104.37 & 7.305 & 3539.07 & 1365.80 \\
\hline 17 & 810.65 & 3.239 & 104.37 & 7.305 & 3539.07 & 1365.80 \\
\hline 18 & - & - & 92.20 & - & - & - \\
\hline 19 & 321.5 & 0.0114 & 83.55 & 7.632 & 2436.88 & 165.84 \\
\hline 20 & 508.15 & 15.988 & 2.78 & 2.630 & 1016.20 & 236.59 \\
\hline I & 353.14 & 0.047 & 2.89 & 7.611 & 2642.99 & 378.27 \\
\hline II & 437.65 & 0.131 & 5.76 & 7.554 & 2803.37 & 555.63 \\
\hline III & 592.65 & 0.592 & 6.02 & 7.450 & 3102.80 & 886.06 \\
\hline IV & 695.15 & 1.376 & 6.16 & 7.382 & 3305.79 & 1109.40 \\
\hline $\mathrm{V}$ & 688.65 & 3.239 & 10.35 & 6.935 & 3263.00 & 1199.80 \\
\hline A & 511.31 & 3.239 & 10.35 & 2.685 & 1028.73 & 232.75 \\
\hline B & 467.40 & 1.376 & 16.51 & 2.276 & 826.55 & 152.44 \\
\hline $\mathrm{C}$ & 380.43 & 0.131 & 5.76 & 1.389 & 449.84 & 40.41 \\
\hline D & 353.14 & 0.047 & 8.64 & 1.075 & 334.90 & 18.87 \\
\hline
\end{tabular}


Table 6. Work, efficiency and exergy destruction of turbines and pumps.

\begin{tabular}{|c|c|c|c|c|c|}
\hline Equipment & $\mathrm{w}\left(\mathrm{kJ} \cdot \mathrm{kg}^{-1}\right)$ & $\dot{W}(\mathbf{M W})$ & $\eta_{\text {En }}$ & $\eta_{\mathrm{Ex}}$ & $\dot{I}_{d}(\mathbf{M W})$ \\
\hline High Pressure Turbine (HPT) & 154.74 & 17.75 & 1 & 0.570 & 13.37 \\
\hline Medium \& Low Pressure Turbine (MPT/LPT) & 986.63 & 102.98 & 1 & 0.918 & 9.264 \\
\hline Condenser Extraction Pump (CEP) & 5.85 & 0.539 & 1 & 0.376 & 0.336 \\
\hline Boiler Feeding Pump (BFP) & 26.74 & 3.07 & 1 & 0.742 & 0.792 \\
\hline
\end{tabular}

Table 7. Fuel exergy parameters.

\begin{tabular}{cc}
\hline Correction factor $(\beta)$ & 1.069 \\
Chemical exergy $($ exchem $)$ & $42941.75 \mathrm{~kJ} \cdot \mathrm{kg}^{-1}$ \\
Thermo-mechanical exergy $\left(\mathrm{ex}_{\mathrm{tm}}\right)$ & $40.85 \mathrm{~kJ} \cdot \mathrm{kg}^{-1}$ \\
Fuel exergy $\left(\mathrm{ex}_{\mathrm{f}}\right)$ & $42982.60 \mathrm{~kJ} \cdot \mathrm{kg}^{-1}$ \\
\hline \multicolumn{2}{c}{} \\
Table 8. Boiler efficiency parameters. \\
\hline Heat rate input in the boiler $\left(\dot{Q}_{B}\right)$ & $303.95 \mathrm{MW}$ \\
Energetic efficiency $\left(\eta_{\mathrm{B}, \mathrm{En}}\right)$ & 0.956 \\
Exergetic efficiency $\left(\eta_{\mathrm{B}, \mathrm{Ex}}\right)$ & 0.469 \\
Exergy destruction $\left(\dot{I}_{d}\right)$ & $177.11 \mathrm{MW}$ \\
\hline
\end{tabular}

The second highest exergy destruction rate was in the HPT and the third was in the MPT/LPT. The pumps showed the least exergy destruction rate.

Table 9 shows general cycle parameters. The gross power output is $120.73 \mathrm{MW}$, which is close to the real value of $120 \mathrm{MW}$, and to the value obtained by global balance (Equation 16) of $116.43 \mathrm{MW}$, showing that the energetic analysis is consistent. The calculated net power output is $117.12 \mathrm{MW}$. The cycle energetic efficiency of $36.8 \%$ is significantly lower than the Carnot efficiency $(63.9 \%)$, which indicates that there are several irreversibilities in the cycle, as was seen for each equipment. The cycle exergetic efficiency was $34.4 \%$.

Figures 3 and 4 show the energy and exergy flows in the power plant, respectively. The energetic analysis shows that the heat rejected in the condenser is the greatest loss of energy (58.1\%) in the plant, which may suggest that it is the main source of efficiency decrease in the cycle. However, the exergetic analysis shows that the destruction of exergy in the boiler is the main source of exergy loss in the cycle $(52.1 \%)$, which is much greater than in the turbines $(6.6 \%)$ and the condenser (less than 5\%). Therefore, efforts to make the power plant more efficient should be directed into decreasing the exergy destruction in the boiler.

The Sustainability Index (SI) is also a measurement of the plant efficiency. It was calculated in Equation (34) (Regulagadda et al., 2010) and the result is SI $=1.64$.

Table 9. Cycle parameters.

\begin{tabular}{cc}
\hline Heat rate input in the boiler $\left(\dot{Q}_{B}\right)$ & $303.95 \mathrm{MW}$ \\
Heat rejected in the condenser $\left(\dot{Q}_{C}\right)$ & $187.51 \mathrm{MW}$ \\
$\dot{Q}_{B}-\dot{Q}_{C}$ & $116.43 \mathrm{MW}$ \\
Gross power output $\left(\dot{W}_{g}\right)$ & $120.73 \mathrm{MW}$ \\
Net power output $\left(\dot{W}_{e}\right)$ & $117.12 \mathrm{MW}$ \\
Carnot efficiency $\left(\eta_{\text {Camot }}\right)$ & 0.639 \\
Energy efficiency $\left(\eta_{\text {En }}\right)$ & 0.368 \\
Exergy efficiency $\left(\eta_{\text {Ex }}\right)$ & 0.344 \\
\hline
\end{tabular}

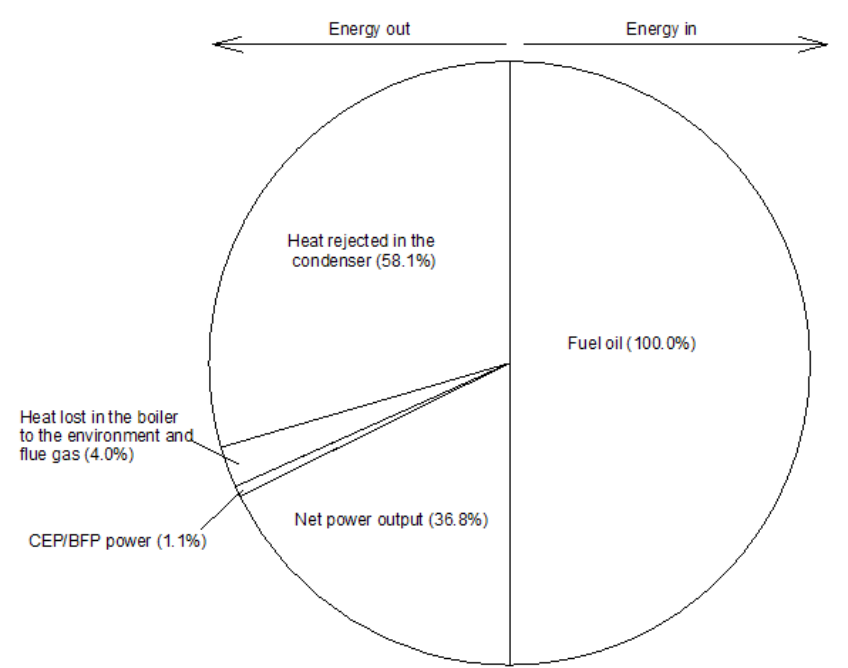

Figure 3. Energy flows in the ppower plant.

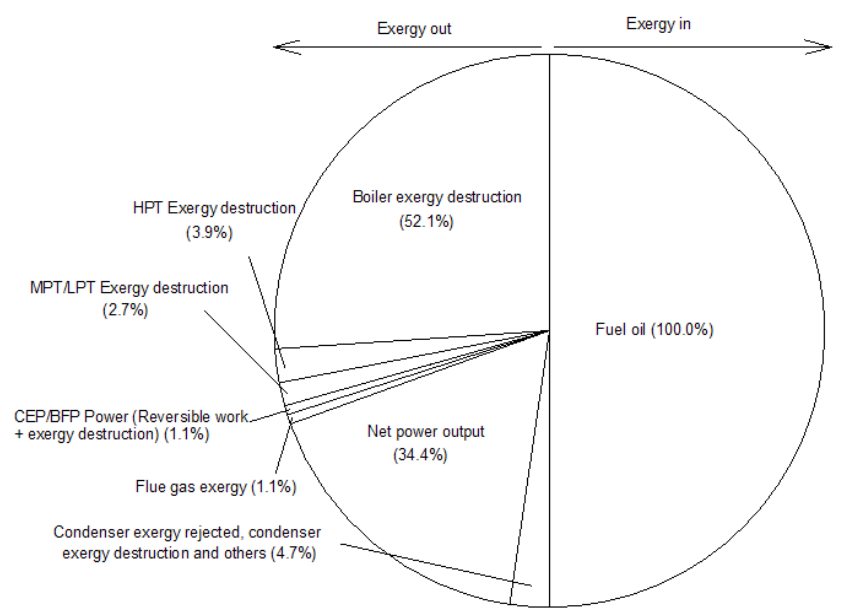

Figure 4. Exergy flows in the power plant.

$S I=\frac{\text { exergyinput }}{\text { exergy destruction }}$

The Improvement Potential Rate $(\dot{I P})$ evaluates how much room for improvement the cycle has. Is was calculated in Equation (35) (Van Gool, 1992) and the result is $\dot{I P}=133.26 \mathrm{MW}$. According to the $\dot{I P}$ value, the power plant might be improved to approximately double its actual capacity.

$$
\dot{I P}=\left(1-\eta_{E x}\right) \cdot \dot{I}_{d}
$$

Table 10 shows data reported in the literature for different power plants. The present work shows 
Table 10. Cycle parameters from the literature.

\begin{tabular}{|c|c|c|c|c|}
\hline Authors & Fuel & $\begin{array}{c}\text { Net power } \\
\text { output (MW) }\end{array}$ & $\begin{array}{c}\text { Energy } \\
\text { efficiency }(\%)\end{array}$ & $\begin{array}{c}\text { Exergy } \\
\text { efficiency }(\%)\end{array}$ \\
\hline $\begin{array}{l}\text { Ontario Power Generation - Lakeview (1969), apud } \\
\text { Rosen and Dincer (2003) }\end{array}$ & Coal & 307 & 35.5 & 33.2 \\
\hline $\begin{array}{l}\text { Ontario Power Generation - Lennox (1970), apud Rosen } \\
\text { and Dincer (2003) }\end{array}$ & Oil & 512 & 37.0 & 34.8 \\
\hline $\begin{array}{l}\text { Ontario Power Generation - Bruce B (1990), apud Rosen } \\
\text { and Dincer (2003) }\end{array}$ & Uranium & 842 & 31.0 & 31.0 \\
\hline $\begin{array}{l}\text { Ontario Power Generation - Nanticoke, apud Rosen and } \\
\text { Dincer (2003) }\end{array}$ & Coal & 500 & 37.4 & 35.8 \\
\hline Aljundi (2009) & Heavy fuel oil & 396 & 26 & 25 \\
\hline Regulagadda et al. (2010) & Coal & 32 & 27.5 & 23.17 \\
\hline Adibhatla and Kaushik (2014) & Coal & 660 & 38.94 & 35.56 \\
\hline
\end{tabular}

significant energetic and exergetic efficiency when compared with other works. Its efficiencies are close to the ones reported by Adibhatla and Kaushik (2014), which are the highest efficiencies listed in Table 10.

\section{CONCLUSIONS}

The analysis of the power plant had adequate considerations and allowed a consistent analysis of the cycle. The gross power output is $120.73 \mathrm{MW}$, which is close to the real value of $120 \mathrm{MW}$. The cycle energetic efficiency is $36.8 \%$, which is significantly lower than the Carnot efficiency of $63.9 \%$, due to the former irreversibilities, but its efficiency is considerable for a 39 year old plant and when compared with the efficiency reported by other authors. The medium pressure turbine (MPT) and the lower pressure turbine (LPT) showed the best efficiencies of the cycle. The boiler showed the greatest exergy destruction rate, while the high pressure turbine (HPT) and the condenser extraction pump (CEP) had the lowest exergy efficiency. The exergy analysis complemented the energy analysis and it had great importance in analyzing the irreversibilities of the process. If the exergetic analysis was not used, the boiler would present $95.6 \%$ of efficiency and all its exergy destruction of $177.11 \mathrm{MW}$ would be neglected. Therefore, the boiler would not be considered the main source of irreversibilities in the cycle. The low efficiency in the high pressure turbine (HPT) and condenser extraction pump (CEP) would also be neglected if no exergy analysis was proposed.

\section{ACKNOWLEDGMENTS}

The authors are grateful for the scholarships granted by the Conselho Nacional de Desenvolvimento Científico e Tecnológico (CNPq) and the financial support granted by Fundação de Amparo à Pesquisa do Estado de Minas Gerais (FAPEMIG) (Edital 01/2016 - Demanda Universal - TEC - APQ-00914-16).

\section{NOMENCLATURE}

$\begin{array}{ll}\mathrm{C}_{\mathrm{p}} & \text { heat capacity }\left(\mathrm{kJ} \mathrm{kg} \mathrm{kg}^{-1} \cdot \mathrm{K}^{-1}\right) \\ \mathrm{ex} & \text { specific exergy }\left(\mathrm{kJ} \cdot \mathrm{kg}^{-1}\right) \\ \mathrm{h} & \text { specific enthalpy }\left(\mathrm{kJ} \cdot \mathrm{kg}^{-1}\right) \\ \dot{\mathrm{m}} & \text { mass flow rate }\left(\mathrm{kg} \cdot \mathrm{s}^{-1}\right) \\ \dot{\mathrm{I}} & \text { exergy destruction rate }(\mathrm{MW}) \\ \mathrm{P} & \text { pressure }(\mathrm{MPa}) \\ \dot{\mathrm{Q}} & \text { heat transfer rate }(\mathrm{MW}) \\ \dot{\mathrm{q}} & \text { specific heat transfer }\left(\mathrm{kJ}^{-} \mathrm{kg}^{-1}\right) \\ \mathrm{s} & \text { specific entropy }\left(\mathrm{kJ} \cdot \mathrm{kg}^{-1} \cdot \mathrm{K}^{-1}\right) \\ \mathrm{T} & \text { temperature }(\mathrm{K}) \\ \dot{W} & \text { work rate }(\mathrm{MW}) \\ w & \text { specific work }\left(\mathrm{kJ} \cdot \mathrm{kg}^{-1}\right) \\ \mathrm{z} & \text { fuel mass fraction }\end{array}$

\section{Greek \\ $\eta \quad$ efficiency}

\begin{tabular}{ll}
\multicolumn{2}{l}{ Subscript } \\
0 & reference properties \\
a & air \\
B & boiler \\
C & condenser \\
chem & chemical \\
e & net output \\
En & energetic \\
Ex & exergetic \\
f & fuel \\
fg & flue gas \\
g & gross output \\
in & input value \\
L & loss \\
out & output value \\
P & pump \\
rev & reversible \\
S & isoentropic \\
T & turbine \\
tm & termo-mechanical
\end{tabular}
Abbreviations
BFP boiler feed pump
CEP condensate extraction pump
DE deaerator 
ECO economizer

HPH high pressure heater

HPT high pressure turbine

LHV lower heating value $\left(\mathrm{kJ} \cdot \mathrm{kg}^{-1}\right)$

LPH low pressure heater

LPT low pressure turbine

MPT medium pressure turbine

$\mathrm{RH}$ reheater

SH superheater

WWT water wall tubes

\section{REFERENCES}

Adibhatla, S., and Kaushik, S.C., Energy and exergy analysis of a super critical thermal power plant at various load conditions under constant and pure sliding pressure operation. Applied Thermal Engineering, 73(1), 49-63 (2014).Available at: http:// dx.doi.org/10.1016/j.applthermaleng.2014.07.030.

Aljundi, I.H., Energy and exergy analysis of a steam powerplantinJordan.AppliedThermalEngineering, 29(2-3), 324-328 (2009).. Available at: http:// dx.doi.org/10.1016/j.applthermaleng.2008.02.029.

Aminov, Z., Nakagoshi, N., Xuan, T.D., Higashi, O., and Alikulov, K., Evaluation of the energy efficiency of combined cycle gas turbine. Case study of Tashkent thermal power plant, Uzbekistan. Applied Thermal Engineering, 103, 501-509 (2016). Available at: http://dx.doi.org/10.1016/j. applthermaleng.2016.03.158

Araújo,A.C.B., Vasconcelos, L.G.S., Fossy, M.F., and Brito, R.P., Exergetic and economic analysis of an industrial distillation column. Brazilian Journal of Chemical Engineering, 24(3), 461-469 (2007). Available at: http://dx.doi.org/10.1590/S0104-66322007000300015

Borba, B.S.M.C., Lucena, A.F.P., Rathmann, R., Costa, I.V.L., Nogueira, L.P.P., Rochedo, P.R.R., Branco, D.A.C., Júnior, M.F.H., Szklo, A., and Schaeffer, R., Energy-related climate change mitigation in Brazil: Potential, abatement costs and associated policies. Energy Policy, 49, 430-441 (2012). Available at: https://doi.org/10.1016/j.enpol.2012.06.040

Kamate, S.C. and Gangavati, P.B., Exergy analysis of cogeneration power plants in sugar industries. Applied Thermal Engineering, 29(5-6), 1187-1194 (2009). Available at: http://dx.doi.org/10.1016/j. applthermaleng.2008.06.016.

Kaushik, S.C., Manikandan, S. and Hans, R., Energy and exergy analysis of thermoelectric heat pump system. International Journal of Heat and Mass Transfer, 86, 843-852 (2015). Available at: http://dx.doi. org/10.1016/j.ijheatmasstransfer.2015.03.069.
Ministério de Minas e Energia (MME) - Brazilian Electrical System Monitoring - 2017. pp.15 Available at: http://www.mme.gov.br/ documents/10584/4475726/Boletim+de+Mon itoramento $+\mathrm{do}+\mathrm{Sistema}+\mathrm{E} 1 \% \mathrm{C} 3 \% \mathrm{~A} 9$ trico ++Janeiro-2017.pdf/18c00330-e3d9-4534-a9f173af3e989604 Acess: Aug. 2017.

Pambudi, N.A., Itoi, R., Jalilinasrabady, S., and Jaelani, K., Exergy analysis and optimization of Dieng single-Flash geothermal power plant. Energy Conversion and Management, 78, 405-411 (2014). Available at: http://dx.doi.org/10.1016/j. enconman.2013.10.073

Rego, E.E., Reserve price: Lessons learned from Brazilian electricity procurement auctions. Energy Policy, 60, 217-223 (2013). Available at: http:// dx.doi.org/10.1016/j.enpol.2013.05.007.

Regulagadda, P., Dincer, I. and Naterer, G.F., Exergy analysis of a thermal power plant with measured boiler and turbine losses. Applied Thermal Engineering, 30(8-9), 970-976 (2010). Available at: http://dx.doi.org/10.1016/j. applthermaleng.2010.01.008.

Rosen, M.A. and Dincer, I., Exergoeconomic analysis of power plants operating on various fuels. Applied Thermal Engineering, 23(6), 643-658 (2003).

Sordi, A., Silva, E.P., Milanez, L.F., Lobkov, D.D., and Souza, S.N.M., Hydrogen from biomass gas steam reforming for low temperature fuel cell: energy and exergy analysis. Brazilian Journal of Chemical Engineering, 26(1), 159-169 (2009). Available at: http://dx.doi.org/10.1590/S010466322009000100015

Utlu, Z., Sogut, Z., Hepbasli, A., and Oktay, Z., Energy and exergy analyses of a raw mill in a cement production. Applied Thermal Engineering, 26(1718), 2479-2489 (2006). Available at: https://doi. org/10.1016/j.applthermaleng.2005.11.016

Szargut J., Morris., D.R. and Steward, F.R., Exergy Analysis of Thermal, Chemical and Metallurgical Process. Hemisphere Publishing Corporation, New York, 332p. (1988)

Zittau's Fluid Property Calculator. Zittau/Goerlitz University of Applied Sciences, Faculty of Mechanical Engineering. Acess: April 2017. Available at: https://web1.hszg.de/thermo_fpc/ index.php

Van Gool, W., Exergy analysis of industrial processes. Energy 17(8), 791-803 (1992). Available at: https:// doi.org/10.1016/0360-5442(92)90123-H 
